\title{
Polycystic Ovarian Syndrome: A Hormonal and Radiological Correlation
}

\author{
Haque Riyajul Aqbalul Nazma Begum ${ }^{1}, \mathrm{~K}$ Ashoka Reddy ${ }^{2}$, Md. Kaleemullah ${ }^{3}$ \\ ${ }^{1}$ Final Year Post Graduate, ${ }^{2}$ Senior Resident, ${ }^{3}$ Final Year Post Graduate, Department of Radiodiagnosis, Father Muller Medical \\ College, Mangaluru, India
}

Corresponding author: Haque Riyajul Aqbalul Nazma Begum, Final Year Post Graduate, Department of Radiodiagnosis, Father Muller Medical College, Mangaluru Pin 575002, India

DOI: http://dx.doi.org/10.21276/ijcmsr.2018.3.4.1

How to cite this article: Haque Riyajul Aqbalul Nazma Begum, K Ashoka Reddy, Md. Kaleemullah. Polycystic ovarian syndrome: a hormonal and radiological correlation. International Journal of Contemporary Medicine Surgery and Radiology. 2018;3(4):D1-D5.

\section{A B S T R A C T}

Introduction: Polycystic ovarian syndrome (POD) is a complex endocrine disorder of unknown etiology also called SteinLeventhal syndrome. It is characterized by multiple small ovarian cysts. These cysts are thought to represent graafian follicles that persist in arrested stages of development because of low levels of FSH. PCOS is commonly associated with insulin resistance, hyperinsulinemia, components of the Metabolic Syndrome and oligo or anovulatory cycles. The objective of this study was to identify the sonological features of ovaries and to correlate with clinical and biochemical profile of the patients with PCOS.

Material and Methods: Ultrasonography was performed in the patients clinically suspected of having polycystic ovarian syndrome and their biochemical indices were determined. Previously established cases of polycystic ovarian syndrome on treatment and patients with any other known health problems were excluded.

Results: Among 102 patients with clinical features of polycystic ovarian syndrome $87 \%$ were under 25 years and $81.60 \%$ were unmarried. Oligomenorrhea was the main complaint in all the subjects and overweight in $45 \%$. Ultrasonography identified $2-9 \mathrm{~mm}$ follicles in $77.45 \%$. Ovarian volume was $\geq 10 \mathrm{cc}$ in $57.84 \%$ of the patients. FSH levels were low in $87.25 \%$ of cases. LH levels were raised in $89.21 \%$ and in $78.43 \%$ testosterone levels were high. FSH, LH levels showed significant and positive correlation with follicle number, follicle size. Testosterone also showed significant and positive correlation with follicle number.

Conclusion: The sonological ovarian features in patients with clinical suspicion of polycystic ovarian syndrome correlated well with clinical and biochemical indices in statistically significant number

Key words: Polycystic Ovarian Syndrome, Hormonal, Radiological

\section{INTRODUCTION}

Polycystic ovarian syndrome (POD) is a complex endocrine disorder of unknown etiology also called Stein-Leventhal syndrome. It is characterized by multiple small ovarian cysts. These cysts are thought to represent graafian follicles that persist in arrested stages of development because of low levels of FSH. ${ }^{1}$ PCOS is commonly associated with insulin resistance, hyperinsulinemia, components of the Metabolic Syndrome, and oligo anovulatory cycles. It is obvious that early diagnosis in adolescent age group would allow us for earlier treatment. One third of patients with clinical manifestations of POD have normal ovaries.

The classic sonographic features of polycystic ovaries are enlarged ovaries, with multiple 2 to $6 \mathrm{~mm}$ cysts, absence of cysts greater than $1.5 \mathrm{~cm}$ in diameter and presence of hyperechoic ovarian stroma. The small cysts may be peripherally located or dispersed throughout the ovarian parenchyma. ${ }^{2-5}$

Study objective was to assess the sonographic appearance of ovaries with transabdominal ultrasonography in female patients of reproductive age group with clinical features of polycystic ovarian syndrome and to determine the association between sonological appearance of ovaries with hormonal profile of the patients with PCOS.

\section{MATERIAL AND METHODS}

\section{Source of data}

Patients in age group of 15-35 years referred from the Obstetrics and Gynaecology, Endocrinology and other departments to department of Radio diagnosis, Father Muller Medical College Hospital, Mangalore for pelvic ultrasound were included in this study. The study period was 18 months from January 2017 to June 2018 .

\section{Method of collection of data}

A prospective study of 102 female patients in reproductive age group. 
Plan of study: Patients referred to radiology department from the Obstetrics and Gynaecology,Endocrinology and other departments to department of Radio diagnosis, Father Muller Medical College Hospital, Mangalore for pelvic ultrasound for suspected PCOS based on clinical details or known case of PCOS were included in this study after informed consent and sonographic appearance of ovaries with transabdominal ultrasonography in female patients of reproductive age group with clinical features of polycystic ovarian syndrome and correlated with various hormonal parameters. No financial burden was incurred on the patient. Ethical clearance was taken from ethics committee of father muller medical college hospital.

\section{Equipment and protocol}

Transabdominal Ultrasonography

The study was performed using Philips IU 22, PHILIPS Affinity 50 And Toshiba Xario ultrasound scanners using convex probes of frequency ranging from 2 to $6 \mathrm{MHZ}$.

\section{Preparation and the procedure included}

- Patients were advised to drink water

- The patients were asked not to void at least for one hour before the examination

- The scan was performed when the urinary bladder was sufficiently distended.

- The scan was performed with the patients in supine position and with abdomen and pelvis adequately exposed.

\section{Inclusion criteria}

Patients referred from Obstetric and Gynecology, Endocrinology and others also departments with clinical suspicion of features of polycystic ovarian syndrome for pelvic sonography. The specific inclusion criteria included were the following:

- Female patients in reproductive age group (15 - 35 years)

- Irregular or no Menstrual periods

- Hirsuitism / Acne (Androgen excess)

- Infertility

- Obesity

- $\quad$ Suspected case of PCOD with hormonal investigations.

\section{Exclusion criteria}

- Known cases of Polycystic ovarian syndrome on treatment and follow up
- Less than 15 years or greater than 35 years agegroup

- Patients without hormonal investigations

\section{RESULTS}

The age range of 102 patients with clinically suspected polycystic ovary syndrome was 15 to 35 years. The mean age distribution was 22 years. Majority (87\%) of the patients were below 25 years. Maximum cases were seen in the group of 19 to 25 years. Majority (81.6\%) of the patients were unmarried.

All of the patients had oligomenorrhea (100\%) and other main complaints were obesity $65.36 \%$, hirsutism $48.78 \%$ and infertility $18.89 \%$.

$65.9 \%$ patients were overweight and $38.87 \%$ were obese. Mean value of BMI was 29.

Trans abdominal ultrasound examination was performed in all patients.

Most(69\%) of the patients showed more than 12 follicles per ovary and peripheral arrangement of the follicles was the most common finding in these patients and it was observed in all. Maximum number of the patients showed follicles of size $2-9 \mathrm{~mm}$ (Table 1 ).

In $58 \%$ of the patients volume was more $10 \mathrm{cc}$. Volume range was $9 \mathrm{cc}$ to $21 \mathrm{cc}$ (table 2).

Most (90.5\%) of the patients were managed medically. $9.4 \%$ were underwent Ovulation induction.

The percentage of patients that showed normal or low levels of FSH values was about $87.25 \% .89 .21 \%$ of the patients had elevated LH levels. $78.43 \%$ of the patients showed elevated testosterone levels. Prolactin (61\%), TSH (93.13\%) levels were normal or low in most of the patients (table 3 ).

FSH levels were low/ normal in $89 \%$ of the patients with ovary volume $\geq 10 \mathrm{cc}$ and the $92.40 \%$ of the patients with follicular size between $2-9 \mathrm{~mm}$. There is a positive correlation between number of follicles, follicular size, volume of ovary and low FSH levels. FSH were low in about $92 \%$ patients with more than 12 follicles (Table 3). $74.69 \%$ of the patients with follicular size $2-9 \mathrm{~mm}$ showed increased levels of LH. There is a positive correlation between follicular size and LH. 75.49\% of the patients with ovary volume $\geq 10 \mathrm{cc}$ showed positive and statistically significant rise in LH levels. $81.31 \%$ of the patients with $\geq 12$ follicles showed statistically significant raise in LH values (Table 3 ).

$82.86 \%$ of the patients with $\geq 12$ follicles and $68.75 \%$ of the

\begin{tabular}{|l|c|c|c|c|c|}
\hline Follicle distribution & Number of patients (N) & Percentage (\%) & Number of follicles & Number of patients (N) & Percentage (\%) \\
\hline Irregular & - & 0 & $<12$ & 32 & 31.37 \\
\hline Peripheral & 102 & 100 & $\geq 12$ & 70 & 68.63 \\
\hline Total & 102 & 100 & Total & 102 & 100 \\
\hline \multicolumn{7}{|r|}{ Table-1: Showing follicular distribution and numbers of follicles per ovary } \\
\hline
\end{tabular}

\begin{tabular}{|l|c|c|c|c|c|}
\hline Follicle size (in mm) & $\begin{array}{c}\text { Number of } \\
\text { patients (N) }\end{array}$ & Percentage (\%) & $\begin{array}{c}\text { Volume of the } \\
\text { ovary (in cc) }\end{array}$ & $\begin{array}{c}\text { Number of } \\
\text { Patients }\end{array}$ & Percentage (\%) \\
\hline $2.0-9.0$ & 79 & 77.45 & $<10$ & 43 & 42.16 \\
\hline$>9.0$ & 23 & 22.55 & $\geq 10$ & 59 & 57.84 \\
\hline Total & 102 & 100 & Total number & 102 & 100 \\
\hline \multicolumn{7}{|r|}{ Table-2: Showing follicular size and volume of the per ovary } \\
\hline
\end{tabular}




\begin{tabular}{|c|c|c|c|}
\hline Hormones & $\begin{array}{c}\text { Number } \\
\text { of } \\
\text { patients }\end{array}$ & $\%$ & \\
\hline \multicolumn{3}{|l|}{$\mathrm{FSH}$} & \multirow[t]{3}{*}{$3.3-8.8 \mathrm{~m} \mathrm{IU} / \mathrm{ml}$} \\
\hline$\leq 10.5 \mathrm{mlU} / \mathrm{L}$ & 89 & 87.25 & \\
\hline$>10.5 \mathrm{~m} \mathrm{IU} / \mathrm{L}$ & 13 & 12.75 & \\
\hline \multicolumn{3}{|l|}{ LH } & \multirow{3}{*}{$0.6-6.2 \mathrm{mlU} / \mathrm{ml}$} \\
\hline$\leq 6.7 \mathrm{IU} / \mathrm{L}$ & 11 & 10.79 & \\
\hline$>6.7 \mathrm{IU} / \mathrm{L}$ & 91 & 89.21 & \\
\hline \multicolumn{3}{|l|}{ TSH } & \multirow{3}{*}{$0.3-4.5 \mathrm{ulU} / \mathrm{ml}$} \\
\hline$<6.5 \mathrm{ulU} / \mathrm{ml}$ & 65 & 63.73 & \\
\hline$>6.5 \mathrm{uu} / \mathrm{ML}$ & 37 & 36.27 & \\
\hline \multicolumn{3}{|l|}{ Testosterone } & \multirow{3}{*}{$1.5-8.1 \mathrm{ng} / \mathrm{ml}$} \\
\hline$<10 \mathrm{ng} / \mathrm{ml}$ & 22 & 21.57 & \\
\hline$>10 \mathrm{ng} / \mathrm{ml}$ & 80 & 78.43 & \\
\hline \multicolumn{3}{|l|}{ Prolactin } & \multirow{3}{*}{$3-20 \mathrm{ng} / \mathrm{ml}$} \\
\hline$<20 \mathrm{pg} / \mathrm{ml}$ & 61 & 59.80 & \\
\hline$>20 \mathrm{pg} / \mathrm{ml}$ & 41 & 40.20 & \\
\hline
\end{tabular}

patients from $<12$ follicle group are positively associated with high testosterone levels. When considering the volume of the ovary $77.97 \%$ of the patients with $\geq 10 \mathrm{cc}$ volume and $79.07 \%$ with $<10 \mathrm{cc}$ volume showed positive relation with rise of testosterone levels. Similarly follicular size also showed positive relation with the rise in testosterone levels (Table 3).

The number of follicles, follicular size, stromal thickness and the volume of ovary showed average positive correlation with the rise of TSH.56.25\% patients were low or normal TSH, 43.75\% patients were showed high TSH level (Table 3).

In our study, the number of follicles, follicular size and the volume of ovary showed weak negative correlation with the rise of prolactin levels.

\section{DISCUSSION}

\section{Age wise distribution of the patients}

Out of 102 patients studied, the mean age of presentation was 22 years. The age range observed was between 15 years to 35 years. Majority (87\%) of the patients were below 25 years. The maximum numbers of patients were in the age group of $19-25$ years $(81.06 \%)$ which is compared with following studies:

According to study conducted by Luciano G.Nardo and William M.Buckettet $\mathrm{al}^{6}$, the mean age was $31 \pm 3$.1years with age range of 26 to 37 years.

In study by S. Jonard, Y.Robert et $\mathrm{al}^{7}$ the age range was 21 to 34 years with a median age of 27 years. It is a prospective study of 214 patients of polycystic ovarian syndrome.

The range of age was 14 to 37 years with a mean age of 24 years in a study of 104 patients, diagnosed as having polycystic ovarian syndrome by Hsu-Chong Yeh and Walter Futterweit. $^{8}$

In the present our study out of 102 patients with suspected polycystic ovarian syndrome most $(81.6 \%)$ of them were unmarried compared to the married (19.4\%).

\section{Chief complaints of the patients}

In the our study all of the patients (100\%) had irregular periods particularly oligomenorrhea. The other main complaints of the patients were obesity which constituted about $65.36 \%$ of the patients followed by $48.78 \%$ of hirsutism and infertility $19.4 \%$. which is close to the study by Adams et $\mathrm{al}^{9}$ and Luciano G. Nardo et al. In this study along with oligomenorrhea (100\%), infertility (85\%) and hirsutism (65\%) were the main complaints of the patients with polycystic ovarian syndrome.

Study by Nagamani Peri et ${ }^{10}$ al in 245 patients with polycystic ovarian syndrome, 146 showed menstrual irregularities, 38 had hirsutism, 15 had infertility 71 had a history of PCOS based on prior evidence; and 78 had a combination of these findings

\section{BMI}

In our study there were $65.9 \%$ patients were overweight and $38.87 \%$ were obese. Mean value of BMI was 29 which is correlated with study by Insler $\mathrm{V}$ and Shoham $\mathrm{Z} .{ }^{11}$ which showed $50 \%$ of the patients were obese with BMI $>25 \mathrm{~kg} /$ $\mathrm{m} 2$ and study by S.Jonard et al of 214 polycystic ovarian syndrome patients the median value of BMI was $26.7 \mathrm{~kg} / \mathrm{m} 2$ with a range of 20 to $40 \mathrm{~kg} / \mathrm{m} 2$.

\section{Type of ultrasound performed}

In the our study of 102 patients transabdominal ultrasonography was done in all patients. Most of the present study population were unmarried $(81.06 \%)$ and young, i.e. $81 \%$ were below 30 years because of that most of the patients opted for transabdominal examination.

\section{Follicles number per ovary}

Most $(68.63 \%)$ of the patients showed more than 12 follicles per ovary and peripheral arrangement of the follicles (means $12 \pm 3$ ). This cut off point was taken as per the Rotterdam consensus definition of polycystic ovarian syndrome. If the cut off point was $\geq 10$ follicles following the criteria of Adams et al, $100 \%$ of the showed more than 10 follicles.

\section{Size of follicle}

77.45\% patients were had follicles measures $2-9 \mathrm{~mm}$ and $22.55 \%$ patients had more than $12 \mathrm{~mm}$ follicles (mean 3.5 $\mathrm{mm}$ follicles) and and $<2 \mathrm{~mm}$ in none. This could be because of the insensitivity of size of follicle in the ultrasound machine to detect the follicles less than $2 \mathrm{~mm}$ and patients body habitus which is correlated with study done by Adams et al, Polson et al, Conway et $\mathrm{al}^{12}$ who stated that findings in our study are $2-9 \mathrm{~mm}$ was the most common (>60\%) follicular size in patients with polycystic ovarian syndrome. Hann et $\mathrm{al}^{13}$ found that mean follicular size was $5 \mathrm{~mm} \pm 1$, with range 2 to $12 \mathrm{~mm}$, and most common follicular size observed was $2-9 \mathrm{~mm}(80 \%)$. Adams et al described $<8 \mathrm{~mm}$ was the most common size of the follicle.

\section{Ovarian volume}

The volume range observed in the present study was between 9 to $19 \mathrm{~mm}$ When $\geq 10 \mathrm{cc}$ was taken as the criteria for polycystic ovarian syndrome our study was observed $\geq$ $10 \mathrm{cc}$ volume in more than half $(57.16 \%)$ of the patients 
and in $42.84 \%$ the volume was less than $10 \mathrm{cc}$ and which is less when compared with study done by Adams et al, who told that most $70 \%$ of the PCOS patients showed $\geq 10 \mathrm{cc}$. and Hann et. $\mathrm{al}^{13}$., study showed $\geq 10 \mathrm{cc}$ in $71 \%$ and normal ovarian volume in about $29 \%$.

\section{Distribution according to biochemical profile}

In our study $87.25 \%$ of the patients showed normal or low levels of FSH. $89.21 \%$ of the patients showed increased $\mathrm{LH}$ levels. The testosterone levels were raised in most (80\%) of the patients. $61 \%$ of the patients showed normal prolactin levels and $65 \%$ of the patients showed normal TSH levels. These results are comparable to other studies by Miguel Dolz and Van Der Westhuitzen. ${ }^{14}$

\section{Correlation between ovarian features and hormonal profile}

Significant rise was seen LH levels in patients with above 12 follicles (81.31\%), with follicular size $2-9 \mathrm{~mm}$ (74.69\%) and > 9mm (91.31\%). Higher testosterone levels were observed in patients with $\geq 12$ follicle. This rise was statistically significant. Higher levels of testosterone were also observed in patients with $\geq 10 \mathrm{cc}$ volume which was $77.97 \%$ and $78.49 \%$ of patients showed raised testerone levels with 2- $9 \mathrm{~mm}$ follicular sizes. In our study observed a positive correlation between low FSH and sonological ovarian features. FSH levels were lower to normal in patients with $\geq 10$ cc $(89.47 \%)$ volume and with follicle size between 2-9 $\mathrm{mm} 92.40 \%$. The follicular size and volume of the ovary showed weak positive correlation with the rise in $\mathrm{TSH}$. All these results were correlated with study by Luciano G. Nardo et al, the total ovarian volume, total follicular volume and follicular number correlated well with the LH and FSH, Study by Miguel Dolz, observed statistically significant correlation between $\mathrm{LH}$ and follicular number. Takahashi et $\mathrm{al}^{15}$ noted a positive correlation between number of small follicles $(2-8 \mathrm{~mm})$ and serum testosterone level, Pache et $\mathrm{al}^{16}$ found positive correlation between testosterone and $\mathrm{LH}$ with number of follicles $>2 \mathrm{~mm}$.

\section{CONCLUSION}

PCOS is one of the common endocrine disorder in young female patients. This is well documented in our study as 85 percent of patients were under 25 years of age.Ultrasonography helps to assess the sonographic charecteristics of the ovaries in PCOS. Although transvaginal sonography has better resolution than transabdominal sonography, in our study we assessed ovaries using transabdominal sonography as predominant patients in our study were unmarried. In our study it was shown that predominant population with PCOS has bulky ovaries with multiple follicles greater than 12 in number which are small in size $<9 \mathrm{~mm}$ in size. All of the above mentioned sonographic features showed good correlation with blood levels of FSH,LH and testesterone. There was average correlation with TSH.In our study there was poor correlation with prolactin levels.

\section{List Of Abbreviations Used}

LH - Luetinizing hormone

TSH - Thyroid stimulating hormone
FSH - Follicle stimulating hormone PCOS - Polycystic ovarian syndrome $\mathrm{N}$ - Number

\section{REFERENCES}

1. Collins JI and Woodward PJ. Radiological Evaluation of Infertility: Seminars in Ultrasound, CT and MRI 1995;16(4):304-16.

2. Mendelson EB, Friedman H, Neiman HL, et al. The role of imaging in infertility management. AJR AM J Roentgenol 1985;144(2):415-20.

3. El Tabbakh GH, Lofty I, Azab I, et al. Correlation of sonographic ovarian disease and the clinical, hormonal, and laparoscopic findings. Am J Obstet Gynecol 1986;154(3):892-95.

4. Yeh H-C, Futterweit W, Thornton JC. Polycystic ovarian disease: US features in 104 patients. Radiology 1987;163(6):111-16.

5. Pache TD, Wladimiroff JW, Hop WCJ, et al. How to discriminate between normal and polycystic ovaries: Transvaginal US study. Radiology 1992;183(3):421-23.

6. Luciano GN, William Buckest M, Daviana White, Alessandro Digesu G, Stephen Franks, Vik Khullar. Three dimensional assessment of ultrasound features in women with Clomiphene citrate-resistant polycystic ovarian syndrome (PCOS): ovarian stromal volume does not correlate with biochemical indices. Human reproduction 2002;17:1052-1055.

7. Jonard S, Robert Y, Cortet-Rudelli C, Pigny P, Decanter C, Dewailly D. Ultrasound examination of polycystic ovaries: is it worth counting the follicles? Human reproduction 2003; 18(3):598-603.

8. Hsu-Chong Yeh, Walter Futterweit, John Thornton C. Polycystic ovarian disease: US features in 104 patients. Radiology 1987;163(5):111-116.

9. Adam HB, Joop SE, Seang-Lin Tan, Didier Dewailly. Ultrasound assessment of the polycystic ovary: international consensus definitions. Human Reproduction Update 2003; 9(2):505-514.

10. Nagamani Peri, Deborah Levine. Sonographic evaluation of the endometrium in patients with a history or an appearance of polycystic ovarian syndrome. J Ultrasound Med 2007; 26(5):55-58.

11. Insler V, Shoham Z, Baraash A, Koistinen R, Seppala M, Hen M, Lunenfeld B, Zadik Z. Polycystic ovaries in non-obese and obese patients: possible pathophysiological mechanism based on new interpretation of facts and findings. Human Reproduction 1993; 8(3):379-84.

12. Conway, G.S., Honour, J.W. and Jacobs, H.S. Heterogeneity of the polycystic ovary syndrome: clinical, endocrine and ultrasound features in 556 patients. Clin. Endocrinol. (Oxf.) 1989;30(4):459-470.

13. Hann LE, Hall DA, Mc Ardle CR, Seibel M. Polycystic ovarian disease: sonographic spectrum. Radiology 1984; 150(2):531-534.

14. Miguel Dolz, Newton G, Osborne, Javier Blanes, Francisco Raga, Lorenzo Abad-Velasco et al. Polycystic ovarian syndrome: Assessment with color Doppler angiography and three dimensional ultrasonography. J Ultrasound Med 1999;18(1):303- 
313.

15. Takahashi K, Eda Y, Abu Musa A, Okada S, Yoshino K, Kitao M. Transvaginal ultrasound imaging, histopathology and endocrinopathy in patients with polycystic ovarian syndrome. Human Reproduction 1994; 9(6):1231-1236.

16. Pache TD, Wladimiroff JW, Hop WC, Fauser BC, How to discriminate between normal and polycystic ovaries: trans-vaginal ultrasound study, Radiology 1992;183 (2):421-423.

Source of Support: Nil; Conflict of Interest: None

Submitted: 02-09-2018; Accepted: 01-10-2018; Published online: 11-10-2018 